\section{Paolo Fornara ${ }^{a}$ \\ Stephan Madersbacher ${ }^{b}$ \\ Winfried Vahlensieck ${ }^{c}$ \\ Franz Bracher ${ }^{d}$ \\ Imre Romics ${ }^{e}$ \\ Paul Kilf}

${ }^{a}$ Clinic of Urology and Transplantation, Martin Luther University of HalleWittenberg, Halle (Saale), Germany; ${ }^{b}$ Department of Urology, Kaiser Franz Josef Hospital, Vienna, Austria; ' Department of Urology, Kurpark-Klinik, Bad Nauheim,

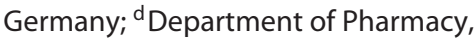
Ludwig-Maximilians-Universität München,

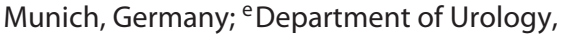
Semmelweis University, Budapest, Hungary; fDepartment of Urology, St. Elisabeth Hospital, Tilburg, The Netherlands

\title{
Phytotherapy Adds to the Therapeutic Armamentarium for the Treatment of Mild-To-Moderate Lower Urinary Tract Symptoms in Men
}

\begin{abstract}
Background: Practice guidelines hardly recommend herbal extracts for male lower urinary tract symptoms (LUTS). However, many patients are unsatisfied with first-line synthetic drugs and often prefer herbal medicines because of good tolerability. To improve the decision-making process, which should consider the patients' expectations, it is crucial to reflect on the role of phytotherapy in the treatment of LUTS. We (panel experts) reflected on current guideline recommendations and real practice across various European countries and debated the potential role of plant extracts with a focus on pumpkin seed soft extract investigated over 12 months in two randomised placebo-controlled trials. Summary: Most guidelines give no clear recommendations on phytotherapy due to the heterogeneity of clinically investigated extracts. Nevertheless, plant extracts are prescribed to patients with mild-to-moderate LUTS. Also, self-medicating patients often handle their complaints with herbal products. Many patients aim to avoid synthetic drugs for fear of sexual functional side effects and a negative impact on their quality of life. For the elderly, vasoactive comedications might be-
\end{abstract}

come an issue. When taking plant extracts, patients experience an acceptable symptomatic relief similar to that achieved with synthetics but without side effects. Key Messages: In shared decision-making for purely symptomatic treatment, a low risk of side effects takes priority. We propose to consider patient preferences in the treatment of mild-to-moderate LUTS in men with a low risk of disease progression. We found a consensus that pumpkin seed soft extract adds to the therapeutic armamentarium for patients who cannot or do not want to apply synthetic drugs.

(c) 2019 S. Karger AG, Basel

\section{Introduction}

In men, lower urinary tract symptoms (LUTS) suggestive of benign prostatic hyperplasia (BPH) are a common condition known for its negative influence on the quality of life. The prevalence of histologic $\mathrm{BPH}$ increases with age [1] and LUTS occur in $62 \%$ of men aged 40 years and older [1]. Consequently, the demographic evolution will karger@karger.com
www.karger.com/uin

(C) 2019 S. Karger AG, Basel

Karger"
Paolo Fornara

Clinic of Urology and Transplantation

Martin Luther University of Halle-Wittenberg, Ernst-Grube-Strasse 40

DE-06120 Halle (Saale) (Germany)

E-Mail paolo.fornara@uk-halle.de 
inflate the prevalence of LUTS in the coming decades. For example, in Germany, the current demographic development suggests that in 2050 nearly $40 \%$ of adults will be over 60 years old and that health insurance services in urology will increase by $20 \%$ [2].

The burden could be even higher, since most men with LUTS do not seek medical help and evade medical treatment. One reason for that is their fear of side effects, especially those related to sexual function [3]. Hence, to adequately manage LUTS and to achieve the most successful outcome, patients' expectations and goals are becoming more and more important and should be considered when deciding on treatment. According to the relevant guidelines issued by national and international associations for urology, the main treatments for LUTS include watchful waiting, medical treatment, and surgical intervention.

Whereas the guidelines closely follow evidence-based concepts and only recommend treatments based on scientific proof of the highest level, the picture in real practice is different and varies considerably across Europe. While there are no clear recommendations on phytotherapy in scientific practice guidelines, patients often prefer herbal remedies. Over the past decades, medicinal plant extracts have been widely and successfully used and prescribed by physicians, especially in Germany, France, Hungary, and Poland [4].

From a professional policy perspective, these prospects make it essential that our focus is not only on the highest level of evidence but also on the actual practice and priorities of the individual patient. Therefore, we (panel experts) reviewed the guideline recommendations, real practice across various European countries, and the potential role of plant extracts with a focus on pumpkin seed soft extract investigated over 12 months in two randomised placebo-controlled trials.

\section{The Pathophysiology of LUTS Is Highly Complex}

The pathophysiology of LUTS is highly complex and the symptoms might be unrelated to the histologic condition of $\mathrm{BPH}$ [5]. Actually, the correlation between LUTS and $\mathrm{BPH}$, benign prostatic enlargement, and bladder outlet obstruction (BOO) is low, and less than $60 \%$ of men with LUTS suggestive of BPH have urodynamically proven $\mathrm{BOO}[6,7]$. On the other hand, detrusor overactivity (DO) occurs in a significant number of patients with and without BOO. Among 1,418 men with symptoms or signs most likely attributable to $\mathrm{BPH}$, pressure flow studies showed DO without BOO in $20 \%$ of the participants, and DO with BOO in around $40 \%$ of the patients [6]. Thus, the term LUTS was introduced to accommodate the recognition that urinary symptoms in men are not always due to prostate enlargement [8].

Particularly the emergence of storage symptoms involves multiple factors related to the bladder, and in individual patients the singular modes of action of synthetic drugs might have limited success. This is one of the reasons why herbal remedies that may offer complex additive effects should not be completely ignored. Importantly, any decision on therapeutic intervention for men with LUTS should be based on an initial assessment of symptom severity and risk of progression.

\section{A Proper Diagnostic Work-Up Should Precede Any Therapy Decision}

Only few patients will develop acute urinary retention or other complications. International and national guidelines provide diagnostic algorithms to identify patients with a risk of disease progression. All of them recommend quantifying LUTS and related bother using validated questionnaires such as the International Prostate Symptom Score (IPSS) with seven symptom questions and one QoL question $[5,9,10]$. However, the EAU points out that symptom scores are neither disease nor age specific. Even low flow rates or high postvoid residual volumes have limited diagnostic value, as both $\mathrm{BOO}$ and inadequate detrusor contractility may be the cause [5]. High levels of prostate-specific antigen (PSA) and a large prostate at baseline are considered the most important indicators of $\mathrm{BPH}$ progression $[5,10,11]$.

Although all guidelines give the same advice regarding procedures to properly diagnose LUTS in men, cross-sectional surveys have identified strong deviations from the recommended approach. In practice, diagnostic measures usually include the determination of PSA levels and assessment of symptoms, but the IPSS was rarely used and, in the greater part of patients, the prostate volume was not assessed $[3,12]$.

\section{Recommended Treatments}

Conservative and medical treatments are recommended to patients with LUTS who do not meet the criteria of surgical intervention guidelines. 


\section{Conservative Treatment}

Most guidelines consider watchful waiting and lifestyle modifications as viable options for many men with mild-to-moderate LUTS [5]. The strength of the recommendation ranges from optional to mandatory depending on the region $[9,10,13,14]$. In some countries, such as the UK or the Netherlands, this approach is strongly supported by the standards of the local health care system.

However, the scientific evidence for successful conservative treatment is limited. The recommendation of lifestyle modifications is only based on 1 study with 140 patients, and the proof of successful watchful waiting mainly consists of results from older studies and the placebo arms of randomised controlled studies $[5,9]$.

\section{The Limits of Standard Pharmacological Treatments}

For patients with moderate-to-severe symptoms and bother, scientific guidelines recommend pharmacological treatments. So far, the mainstays of standard medical management are selective alpha-1 receptor blockers $\left(\alpha_{1}\right.$ blockers) and 5a-reductase inhibitors (5-ARIs).

As the first-line treatment for rapid symptom relief, $\alpha_{1}$-blockers relax the smooth muscles of the bladder neck, urethra, and prostate, and thus alleviate micturition complaints. However, $\alpha_{1}$-blockers only act symptomatically in male LUTS. In contrast to 5-ARIs, they do not slow down prostate growth, nor do they reduce the risk of complications [5].

Additionally, the efficacy of $\alpha_{1}$-blockers in men with predominant storage symptoms may be limited. For these patients, the guidelines suggest add-on treatment with anticholinergics or the $\beta_{3}$ agonist mirabegron. However, long-term studies in men with LUTS are not yet available for these options $[5,15]$.

The phosphodiesterase type 5 inhibitor tadalafil may be offered to men with moderate-to-severe LUTS with or without erectile dysfunction. However, the long-term experience with tadalafil in men with LUTS and the information on disease progression are limited [5].

In line with the recommendations in the guidelines, $\alpha_{1}$-blockers and 5-ARIs are the key pharmaceuticals used in medical practice, whereas $\alpha_{1}$-blockers dominate the present prescription market $[4,16]$. Interestingly, although the disease manifests itself similarly in men across countries, prescription rates according to the IMS Health database display huge discrepancies, with an increase from northern to southern regions (Table 1).

Potential side effects associated with synthetic drugs may have an impact on the individual patient's quality of
Table 1. Prescriptions of $\alpha_{1}$-blockers, 5-ARIs, and plant extracts in Europe

\begin{tabular}{|c|c|c|c|c|}
\hline \multirow[t]{2}{*}{$\mathrm{PI}^{1}$} & \multirow[t]{2}{*}{ Country } & \multicolumn{3}{|c|}{ Distribution, \% } \\
\hline & & plant extracts & 5-ARIs & $a_{1}$-blockers \\
\hline 17 & Norway & 0 & 31 & 69 \\
\hline 18 & Denmark & 0 & 28 & 72 \\
\hline 22 & Ireland & 0 & 45 & 55 \\
\hline 22 & Sweden & 0 & 22 & 78 \\
\hline 23 & Belgium & 41 & 9 & 50 \\
\hline 24 & $\mathrm{UK}$ & 0 & 33 & 67 \\
\hline 28 & Hungary & 43 & 7 & 50 \\
\hline 29 & The Netherlands & 0 & 24 & 76 \\
\hline 29 & Austria & 3 & 21 & 76 \\
\hline 30 & Switzerland & 23 & 17 & 60 \\
\hline 35 & Germany & 20 & 11 & 69 \\
\hline 47 & France & 25 & 17 & 58 \\
\hline 43 & Greece & 2 & 19 & 79 \\
\hline 44 & Czechia & 14 & 16 & 70 \\
\hline 44 & Finland & 0 & 39 & 61 \\
\hline 52 & Italy & 4 & 27 & 69 \\
\hline 53 & Spain & 15 & 19 & 65 \\
\hline 56 & Poland & 9 & 18 & 73 \\
\hline 57 & Portugal & 9 & 35 & 56 \\
\hline
\end{tabular}

5-ARIs, 5a-receptor inhibitors; PI, prescription index. ${ }^{1}$ Total index calculated for the daily use of 5-ARIs, $\alpha_{1}$-blockers, or phytotherapy based on the volume of medications sold to all pharmacies and adjusted for each country. The PI for each drug class was defined as the days of treatment with the drug per year registered in the IMS Health database divided by the number of men potentially at risk ( $30 \%$ of all men $>50$ years of age), divided by 365 days (data according to Gravas et al. [5]).

life and thus influence adherence to treatment. Particularly, older patients with cardiovascular comorbidity and vasoactive comedication maybe susceptible to $\alpha_{1}$-blockerinduced vasodilatation [5, 17]. Both $\alpha_{1}$-blockers and 5-ARIs are associated with various sexual dysfunctions (Table 2). Particularly sexually active men of all ages value the preservation of their current sexual activity and may not accept the risk of side effects affecting their sexual life $[3,18]$. How frequently sexual functional side effects are observed in clinical studies greatly depends on the design. If patients are actively asked about their sexual function, the incidence of related side effects is much higher than if data collection is based on spontaneous reports from patients $[19,20]$. Studies with finasteride and dutasteride showed increased risks of sexual dysfunction, erectile dysfunction, ejaculation disorders, and decreased libido [21]. Also, the occurrence of erectile dysfunction is a known class effect of selective $\alpha_{1}$-blockers $[22,23]$. 
Table 2. Side effects of $\alpha_{1}$-blockers and 5-ARIs on sexual function

\begin{tabular}{llllll}
\hline $\begin{array}{l}\text { Drug class } \\
\text { Substance }\end{array}$ & $\begin{array}{l}\text { Impotence, } \\
\text { erectile } \\
\text { dysfunction }\end{array}$ & $\begin{array}{l}\text { Decreased } \\
\text { libido }\end{array}$ & $\begin{array}{l}\text { Ejaculation } \\
\text { disorders }\end{array}$ & $\begin{array}{l}\text { Breast } \\
\text { disorders/ } \\
\text { enlargement }\end{array}$ & $\begin{array}{l}\text { Priapism } \\
\text { poor sperm } \\
\text { quality }\end{array}$ \\
\hline
\end{tabular}

$a_{1}$-Blockers

Alfuzosin

Doxazosin

Terazosin

Tamsulosin

Silodosin

5-ARIs

Finasteride

Dutasteride

$\times$
$\times$
$\times$
$\times^{1}$
$x^{1}$

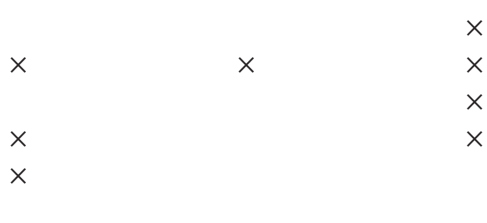

$\begin{array}{lll}x^{1} & \times \\ \times^{1} & \times & \times \\ & x^{1} & \times \\ x^{1} & \times & \times\end{array}$

Tamsulosin/dutasteride $\quad x^{1}$

Source: La Torre et al. [20]; product information on Xatral (alfuzosin), Cardura (doxazosin), Hydrin (terazosin), Flomax (tamsulosin), Urotec (silodosin), Proscar (finasteride), Avodart (dutasteride), and Combodart (dutasteride/tamsulosin). 5-ARIs, 5a-receptor inhibitors. ${ }^{1}$ Persisting after discontinuation.

Table 3. Current recommendations on phytotherapy in guidelines on the treatment of LUTS

\begin{tabular}{|c|c|c|c|c|c|c|c|}
\hline Region/country & Association & Year $^{1}$ & $\mathrm{R}$ & $\mathrm{O}$ & NM & NR & $\mathrm{DO}$ \\
\hline Europe & EAU & 2017 & & & & $x$ & \\
\hline Germany & DGU & 2014 & & $x$ & & & \\
\hline UK & NICE & 2015 & & & & & $\times$ \\
\hline Italy & AURO.it & 2015 & & $\times$ & & & \\
\hline France & CTMH-AFU & 2015 & $\times$ & & & & \\
\hline USA & AUA & 2014 & & & & $x$ & \\
\hline Canada & CUA & $2010^{2}$ & & $\times$ & & & \\
\hline Asia & UAA & 2012 & & & & $x$ & \\
\hline Japan & JUA & 2011 & & $x$ & & & \\
\hline Australia/New Zealand & ANZUNS & 2015 & & & $x$ & & \\
\hline International & ICUD/SIU & 2012 & & & & $x$ & \\
\hline
\end{tabular}

$\mathrm{R}$, recommended as an alternative to prescription drugs; $\mathrm{O}$, optional, can be considered; NM, not mentioned; NR, not recommended; DO, exclusion of use: "do not offer"; EAU, European Association of Urologists [5]; DGU, Deutsche Gesellschaft für Urologie [9]; NVU, Nederlandse Vereniging voor Urologie [52]; NICE, National Institute for Health and Care Excellence [14]; AURO.it, Associazione Urologi Italiani [15]; CTMH-AFU, Comité des troubles mictionnels de l'homme de l'Association française d'urologie [50]; SEMERGEN/ AEU, Sociedad Española de Médicos de Atención Primaria/Asociación Española de Urología [51]; AUA, American Urological Association [53]; CUA, Canadian Urological Association [54]; UAA, Urological Association of Asia [55]; JUA, Japanese Urological Association [56]; ANZUNS, Australia and New Zealand Urological Nurses Society [57]; ICUD/SIU, International Consultation on Urological Diseases/Société Internationale d'Urologie [49]. ${ }^{1}$ Year of publication/last review. ${ }^{2}$ Still valid on the website.

\section{No General Recommendation on Phytotherapy in Guidelines}

Although phytotherapy does not have any side effects and has effected symptomatic relief in clinical trials on men suffering from LUTS, practice guidelines across Europe hardly contain any final recommendation regarding phytotherapy. Guidelines outside Europe show a similar phenomenon: plant extracts are either not mentioned or not recommended (Table 3), mainly due to the heterogeneity of the various extracts available as well as methodological problems, for instance, meta-analyses leading to inhomogeneous proof of efficacy. 
Besides the guideline of the European Association of Urology (EAU), which represents a broad compromise, some countries have national guidelines, which are essentially orientated towards the EAU specification. However, the focus of each guideline may vary depending on the target group (specialists or general practitioners) and the country-specific health care system. For example, in Great Britain, physicians strictly have to follow the recommendations of the NICE guideline, which keeps out herbal medicine. Similarly, in the Netherlands, the guideline-recommended decision aid-guided dialogue between doctors and patients does not include plant extracts either [13, 24].

On the other hand, in Germany, Italy, and France, plant extracts may be an option for treating LUTS, even if only for selected patients. German urologists in particular do not exclude the use of phytotherapy in particular cases [9]. Furthermore, phytotherapy is part of continuing medical education in BPH treatment in Germany [25].

In consequence, physicians' possibilities for prescribing or recommending plant extracts to patients vary across Europe. This circumstance reflects the heterogeneous proportions of plant extract prescription across Europe. In some countries (Ireland, the UK, Denmark, Norway, Finland, and Sweden) phytotherapy is not prescribed at all, whereas it plays a role in other countries such as France, Hungary, Germany, Belgium, and Switzerland (Table 1).

\section{Patients' Perspectives and Preferences}

Population-based surveys have shown that a considerable proportion of patients with LUTS do not consult with a health care provider, for various reasons $[3,26-$ 28]. Urinary tract problems are connected with shame and embarrassment [16]. Other patients simply accept their problems as an inevitable part of the aging process [28]. However, for those patients who seek professional advice, quantitative research in the UK, Poland, and Spain has confirmed the key advisory role of physicians [16].

Symptom worsening and the associated impact on quality of life are the main reasons for men consulting their physician. However, the patients are less concerned about early symptom relief than about long-term risks. They seek disease stabilisation, would like to reduce the risk of surgery, and look for reassurance that they do not have any serious underlying condition such as prostate

Role of Phytotherapy in BPH-related LUTS cancer $[11,12,29,30]$. Patients also fear treatment-associated side effects and might accept a delay in the onset of relief to avoid them. Particularly sexually active patients of all ages value the preservation of their current sexual activity and may not accept the risk of side effects affecting their sexual function $[3,17,18]$.

Selecting the best treatment option for any individual patient with LUTS requires that the patient is well informed about the benefits and risks of all treatment alternatives. Patients will be more satisfied with a treatment decision that takes into account their expectations and preferences. This particularly applies to patients with "oligosymptomatic LUTS," which can be defined as the early stage of disease with mild-to-moderate symptoms and without any identified risk of disease progression in the near future.

Recently issued guidelines suggest a dialogue between physicians and patients to clarify the patients' expectations $[5,9,14,15]$. A structured LUTS/BPH decision aid has been implemented in the Netherlands as a tool for assisting patients in participating in a shared decision on treatment [13].

\section{The Effects of Specific Plant Extracts Are Equal to Those of Prescription Drugs}

If taking into account patients' preferences, it is worth considering using phytotherapy in cases that are only about symptomatic relief and improvement of patients' quality of life. In such cases, any therapy should ideally not lead to an additional impact on the quality of life due to side effects.

LUTS are particularly susceptible to placebo [31]. In fact, randomised controlled trials conducted with synthetic drugs and plant extracts have coherently demonstrated considerable placebo effects which lead to clinically relevant improvements in LUTS after 12 months [32]. Patients always experience placebo and active treatment effects as a sum, and one should be aware that placebo effects account for $40-60 \%$ of the overall improvement. Even with prescription drugs, the therapeutic outcome barely goes beyond the placebo effect. Actually, $\alpha_{1}$-blockers have failed to achieve a clinically meaningful 3-point difference over placebo [31-33].

In clinical trials, the overall symptomatic relief achieved with certain plant extracts has been similar to the results achieved with $\alpha_{1}$-blockers and 5-ARIs [34, 35]. Plant extracts have no negative influence on sexual function or blood pressure. In real-world practice, patients with mild- 
to-moderate LUTS experience symptom relief with plant extracts and would not notice any relevant difference to therapy with $\alpha_{1}$-blockers or 5-ARIs. LUTS patients therefore benefit equally from herbal medicines, but without suffering from significant side effects.

\section{Specific Attributes of Plant Extracts}

In contrast to purely chemical substances, plant extracts have the special feature of a complex composition. The clinical effects of herbal medicines derive from various constituents rather than from the activity of one single molecule.

As with most herbal medications, the modes of action of plant extracts used in the treatment of LUTS are not yet entirely understood. Suggested pharmacological activities include inhibition of $5 \alpha$-reductase, as well as antiinflammatory, anti-androgenic, and oestrogenic effects or interactions with various receptors $[5,9]$. Plant extracts used for the treatment of LUTS contain phytosterols as secondary metabolites, mainly $\beta$-sitosterol or other $\Delta^{5}$-sterols. However, it is hard to believe that these standard $\Delta^{5}$-sterols should be responsible for any pharmacological effects against LUTS or BPH, since the typical daily dose of phytosterols taken with medicinal products is below $100 \mathrm{mg}$, i.e., far lower than the daily dietary intake of 250-300 $\mathrm{mg}$ of $\beta$-sitosterol [36].

In contrast, the specific $\Delta^{7}$-sterols found in pumpkin seeds belong to a distinct class of phytosterols that is not part of the standard daily diet. $\Delta^{5}$ - and $\Delta^{7}$-sterols have different chemical structures regarding the double-bond position in the tetracyclic ring system and the lipophilic branched side chains. An analysis of 31 phytosterol-containing products marketed in Europe for the treatment of $\mathrm{BPH}$ symptoms demonstrated that only pumpkin seed soft extract contains significant amounts of these unique $\Delta^{7}$-sterols. The phytosterols found in conifers and extracts from nettle root or saw palmetto fruit only consist of the ubiquitous $\Delta^{5}$-sterols. Also, other extracts from pumpkin seed do not contain any amounts of $\Delta^{7}$-sterol that are worth mentioning [37].

These small but significant differences imply that the physiological and pharmacological effects of pumpkin seed soft extract are not completely equal to those of the $\beta$-sitosterol-containing plants used to treat LUTS. Efforts to explain the mode of action of pumpkin seed extract have focused on $\Delta^{7}$-sterols. Experimental studies have aimed to elucidate to what extent these unique compounds are responsible for the clinical effects observed.
Today, the modes of action postulated for pumpkin seed include inhibition of dihydrotestosterone (DHT) binding to the cytoplasmatic androgen receptor, and inhibitory effects on the $5 a$-reductase pathway in DHT production. Both mechanisms could reduce the formation of DHT receptor complexes that stimulate prostate growth [38-40]. Not surprisingly, the inhibitory effects of $\Delta^{7}$-sterols are weak when compared to those of finasteride or antiandrogens. This fact coincides with the clinical experience that pumpkin seed extract does not influence PSA values, nor does it cause the typical side effects of finasteride $[41,42]$. Therefore, the postulated mechanisms could only be expected to show clinical effects on prostate size if patients used pumpkin seeds over a longer period than that of the currently available 12-month clinical studies.

However, other mechanisms of lipophilic components of pumpkin seed, such as fatty acids or spinasterol, may explain the short-term beneficial effects, particularly on storage symptoms such as an overactive bladder [43-45].

\section{Clinical Evidence on Pumpkin Seeds}

Due to the complex composition of plant extracts and because the results of experimental studies per se cannot be directly translated into proven therapeutic effects, clinical data obtained using individual plant extracts are even more important. Still, properly conducted studies with adequate sample sizes and study durations are scarce. According to relevant reviews $[5,9,35]$, only 5 randomised trials tested herbal medicines against placebo over 12 months (Table 4).

Two placebo-controlled randomised controlled trials investigated pumpkin seed soft extract (DER: 15-25:1; extraction solvent: ethanol 92\%) in approximately 2,000 patients with LUTS suggestive of BPH. Both studies had a follow-up period of 12 months. The primary efficacy outcome was the response rate, whereby a reduction in IPSS by 5 points was the predefined threshold of response to treatment. In both studies, the LUTS improved progressively in all treatment arms from the start to the end of the study $[41,42]$.

The first study randomised 476 patients to receive either pumpkin seed soft extract (500 mg) or placebo twice a day. At the end of the study, the proportion of patients with an improvement by at least 5 points in IPSS was statistically significantly higher in the pumpkin seed group $(64.8 \%)$ than in the placebo group (54.2\%). A decrease in IPSS was already seen after the first month, albeit simi- 
Table 4. Randomised placebo control studies with plant extracts and a follow-up of 12 months

\begin{tabular}{|c|c|c|c|}
\hline Study [Ref.], year & Treatment & Patients, $n$ & Change in IPSS from baseline \\
\hline \multirow[t]{2}{*}{ Bach [41], 2000} & $\begin{array}{l}\text { Pumpkin seed soft extract } \\
\text { (EA: ethanol } 92 \% \text { ) }\end{array}$ & 233 & $-6.4^{\mathrm{a}}$ \\
\hline & Placebo & 243 & -5.5 \\
\hline \multirow[t]{3}{*}{ Vahlensieck et al. [42], 2015} & $\begin{array}{l}\text { Pumpkin seed soft extract } \\
\text { (EA: ethanol } 92 \% \text { ) }\end{array}$ & 481 & -4.2 \\
\hline & Pumpkin seed & 475 & $-5.4^{\mathrm{a}}$ \\
\hline & Placebo & 474 & -4.0 \\
\hline \multirow[t]{2}{*}{$\begin{array}{l}\text { Schneider and Rübben [46], } \\
2004\end{array}$} & $\begin{array}{l}\text { Stinging nettle root extract } \\
\text { (EA: methanol 20\%) }\end{array}$ & 114 & $-5.7^{\mathrm{a}}$ \\
\hline & Placebo & 112 & -4.7 \\
\hline \multirow[t]{2}{*}{ Bent et al. [47], 2006} & $\begin{array}{l}\text { Saw palmetto extract } \\
\text { (EA: carbon dioxide) }\end{array}$ & 112 & -0.7 \\
\hline & Placebo & 113 & -0.7 \\
\hline \multirow[t]{2}{*}{ Barry et al. [48], 2011 b } & $\begin{array}{l}\text { Saw palmetto extract } \\
\text { (EA: ethanol 90\%) }\end{array}$ & 182 & -2.2 \\
\hline & Placebo & 186 & -3.0 \\
\hline
\end{tabular}

IPSS, International Prostate Symptom Score; EA, extracting agent. ${ }^{a}$ Significant $(p<0.05)$ versus placebo [5, 9, 35]. ${ }^{\mathrm{b}}$ Increasing-dose study over 72 weeks.

larly in both groups. However, with continued treatment, the improvement in the active group became progressively clearer than in the placebo group. After 6 months, the placebo effect ran out, since no further improvement was observed in this group [41].

The second trial compared placebo with pumpkin seed extract and openly administered pumpkin seeds in a sample of 1,431 patients. The patients in all groups experienced progressive symptomatic relief during the 12-month follow-up period. At the end of the study, the response rate of crude pumpkin seeds exceeded that of placebo by $10 \%$. The decrease in IPSS was accompanied by a continuous improvement in IPSS-related quality of life, which was more pronounced in the two pumpkin seed groups than in the placebo group [42].

The incidence of drug-related adverse events was very low and mainly consisted of transient gastrointestinal disorders. PSA levels, blood pressure, heart rate, and safety laboratory test results were not influenced [41, 42].

\section{Conclusions}

National and international guidelines for the management of LUTS in men provide similar recommendations on diagnostic procedures and therapeutic options. However, adherence to the recommended diagnostic algo- rithms is often low, and large-scale population studies have revealed great differences across Europe in the management of LUTS, although the disease manifests itself similarly in patients of all countries. Furthermore, many patients are not satisfied with the treatment options which are recommended in the guidelines and offered by their physicians.

Plant extracts have a considerable share in the treatment of patients with mild-to-moderate LUTS in several EU countries. Even in regions where the primary care system excludes the prescription of plants, a high self-medication rate indicates that patients seek herbal products to handle their complaints.

At present, the modes of action of all the plant extracts used in the treatment of LUTS are not yet entirely understood, because clinical effects cannot be attributed to a precisely defined action of one single molecule. On the one hand, this is a point of criticism against plant extracts; on the other hand, their broader range of effects seems beneficial against diseases with a complex pathophysiology and symptomatology. LUTS consisting of storage and voiding symptoms and related bother vary greatly between individual patients. Consequently, not all patients will benefit from only one molecular mechanism. The limitations of synthetic substances become clear if we look at the need for adding muscarinic receptor antagonists to the therapy with an $\alpha_{1}$-blocker and the introduc- 
tion of $\beta_{3}$ agonists for patients with mainly storage (overactive bladder) symptoms.

According to clinical studies, plant extracts provide a magnitude of symptomatic relief which is comparable to that achieved with synthetic drugs. Thus, for patients with no risk of progression, plant extracts are even advantageous because they are well tolerated and have no contraindications or interactions.

A closer look at guideline recommendations reveals that synthetic substances are only designated for patients who suffer from moderate-to-severe LUTS. Accordingly, for patients with mild-to-moderate symptoms, the guidelines only recommend conservative non-drug measures. However, the evidence for watchful waiting and lifestyle modifications is weak, and not all patients will achieve acceptable symptom relief.

From this point of view, the evidence supporting the use of plant extracts appears to be much more abundant than the evidence supporting the concept of lifestyle modifications. After all, plant extracts have been investigated in a considerable number of studies and were shown to cause symptomatic relief and improvement of the quality of life of BPH patients [5, 9]. Thus, for purely symptomatic treatment, it is debatable whether the risk of drug interactions, adverse events, or undesired effects justifies the widespread recommendation to use synthet- ic drugs, especially in the early stages of LUTS in men. Depending on the specific provisions of each country, phytotherapy may be offered as either an alternative to an $\alpha_{1}$-blocker or as part of a lifestyle scheme.

\section{Acknowledgement}

We would like to thank B. Patz for writing support.

\section{Disclosure Statement}

The authors declare that they have no conflict of interest to disclose.

\section{Funding Sources}

Omega Pharma Deutschland GmbH, Herrenberg, Germany, sponsored the expert panel meeting.

\section{Author Contributions}

All authors contributed to the expert panel and read and approved the final manuscript. P.F. wrote the article.

\section{References}

1 Irwin DE, Milsom I, Hunskaar S, Reilly K, Kopp Z, Herschorn S, et al. Population-based survey of urinary incontinence, overactive bladder, and other lower urinary tract symptoms in five countries: results of the EPIC study. Eur Urol. 2006 Dec;50(6):1306-14; discussion 1314-5.

2 DeStatis, Statistisches Bundesamt. Bevölkerung, Familien, Lebensformen, Bevölkerungsvorausberechnung bis 2060. In: Statistisches Jahrbuch Deutschland. Wiesbaden: Statistisches Bundesamt; 2016. pp. 57-8.

3 Fourcade RO, Théret N, Taïeb C; BPH USAGE Study Group. Profile and management of patients treated for the first time for lower urinary tract symptoms/benign prostatic hyperplasia in four European countries. BJU Int. 2008 May;101(9):1111-8.

4 Cornu JN, Cussenot O, Haab F, Lukacs B. A widespread population study of actual medical management of lower urinary tract symptoms related to benign prostatic hyperplasia across Europe and beyond official clinical guidelines. Eur Urol. 2010 Sep;58(3):450-6.
5 Gravas S, Bach T, Drake MJ, Gacci M, Gratzke C, Herrman TR, et al. Treatment of nonneurogenic male LUTS. 2017. http://uroweb. org/guideline/treatment-of-non-neurogenicmale-luts/. Supplementary online material 2017 [accessed 2019 May 9]. Available from: http://uroweb.org/wp-content/uploads/ EAU-Male-LUTS-Guidelines-supplementary-online-material-2017.pdf.

6 Oelke M, Baard J, Wijkstra H, de la Rosette JJ, Jonas U, Höfner K. Age and bladder outlet obstruction are independently associated with detrusor overactivity in patients with benign prostatic hyperplasia. Eur Urol. 2008 Aug; 54(2):419-26.

7 Soler R, Andersson KE, Chancellor MB, Chapple CR, de Groat WC, Drake MJ, et al. Future direction in pharmacotherapy for non-neurogenic male lower urinary tract symptoms. Eur Urol. 2013 Oct;64(4):610-21.

8 Chapple CR, Wein AJ, Abrams P, Dmochowski RR, Giuliano F, Kaplan SA, et al. Lower urinary tract symptoms revisited: a broader clinical perspective. Eur Urol. 2008 Sep;54(3):563-9.
9 Deutsche Gesellschaft für Urologie. S2e Leitlinie "Therapie des Benignen Prostatasyndroms (BPS)." AWMF-Reg. Nr.: 043-035. 2014.

10 Chua T, Simpson JS, Ventura S. Developments in the Treatment of Sexual Dysfunction and Diseases of the Lower Urinary Tract Fractionation of Saw Palmetto Extracts and Bioassay Fractions in Isolated Rat Prostate. Basic Clin Pharmacol Toxicol. 2010;107(Suppl 1):P08.

11 Speakman M. Lower Urinary Tract Symptoms Suggestive of Benign Prostatic Hyperplasia (LUTS/BPH): More Than Treating Symptoms? Eur Urol Suppl. 2008;7(11):6809.

12 Montorsi F, Mercadante D. Diagnosis of BPH and treatment of LUTS among GPs: a European survey. Int J Clin Pract. 2013 Feb;67(2): $114-9$.

13 Nederlandse Vereniging voor Urologie. Richtlijn, Diagnostiek en behandeling van LUTS/ BPH [accessed 2019 May 9]. 2017. Available from: https://www.nvu.nl/en-us/kwaliteit/ richtlijnen/actuelerichtlijnen.aspx. 
14 NICE. Lower urinar tract symptoms in men: management. Clinical guideline [CG97]. Published date: May 2010. Last updated: June 2015 [accessed 2019 May 9]. Available from: https://www.nice.org.uk/guidance/cg97 (May 10, 2019).

15 Spatafora S, Casarico A, Fandella A, Galetti C, Hurle R, Mazzini E, et al.; RO.it BPH Guidelines Committee. Evidence-based guidelines for the treatment of lower urinary tract symptoms related to uncomplicated benign prostatic hyperplasia in Italy: updated summary from AURO.it. Ther Adv Urol. 2012 Dec; 4(6):279-301.

16 Gesellschaft für Konsumforschung. Quantitative market research in UK, PL, ES. 2013.

17 Watson V, Ryan M, Brown CT, Barnett G, Ellis BW, Emberton M. Eliciting preferences for drug treatment of lower urinary tract symptoms associated with benign prostatic hyperplasia. J Urol. 2004 Dec;172(6 Pt 1):2321-5.

18 Sturch P, Woo HH, McNicholas T, Muir G. Ejaculatory dysfunction after treatment for lower urinary tract symptoms: retrograde ejaculation or retrograde thinking? BJU Int. 2015 Feb;115(2):186-7.

19 Casabé A, Roehrborn CG, Da Pozzo LF, Zepeda S, Henderson RJ, Sorsaburu S, et al. Efficacy and safety of the coadministration of tadalafil once daily with finasteride for 6 months in men with lower urinary tract symptoms and prostatic enlargement secondary to benign prostatic hyperplasia. J Urol. 2014 Mar;191(3):727-33.

20 La Torre A, Giupponi G, Duffy D, Conca A, Cai T, Scardigli A. Sexual Dysfunction Related to Drugs: A Critical Review. Part V: a-Blocker and 5-ARI Drugs. Pharmacopsychiatry. 2016 Jan;49(1):3-13.

21 Liu L, Zhao S, Li F, Li E, Kang R, Luo L, et al. Effect of $5 \alpha$-Reductase Inhibitors on Sexual Function: A Meta-Analysis and Systematic Review of Randomized Controlled Trials. J Sex Med. 2016 Sep;13(9):1297-310.

22 Gandhi J, Weissbart SJ, Smith NL, Kaplan SA, Dagur G, Zumbo A, et al. The impact and management of sexual dysfunction secondary to pharmacological therapy of benign prostatic hyperplasia. Transl Androl Urol. 2017 Apr;6(2):295-304.

23 Lareb Netherlands Pharmacovigilance Centre. Tamsulosin and erectile dysfunction [accessed 2019 May 10]. 2014. Available from: https://databankws.lareb.nl/Downloads/ KWB_2013_4_tamsul.pdf.

24 Lamers RE, Cuypers M, Garvelink MM, de Vries M, Bosch JL, Kil PJ. Development of a decision aid for the treatment of benign prostatic hyperplasia: a four stage method using a Delphi consensus study. Patient Educ Couns. 2016 Jul;99(7):1249-56.

25 Oelke M, Martinelli E. Medikamentöse Therapie des benignen Prostatasyndroms. Urologe A. 2016 Jan;55(1):81-94; quiz 95-6.
26 Garraway WM, Russell EB, Lee RJ, Collins GN, McKelvie GB, Hehir M, et al. Impact of previously unrecognized benign prostatic hyperplasia on the daily activities of middleaged and elderly men. Br J Gen Pract. 1993 Aug;43(373):318-21.

27 Irwin DE, Milsom I, Kopp Z, Abrams P; EPIC Study Group. Symptom bother and health care-seeking behavior among individuals with overactive bladder. Eur Urol. 2008 May; 53(5):1029-37.

28 Speakman M, Kirby R, Doyle S, Ioannou C. Burden of male lower urinary tract symptoms (LUTS) suggestive of benign prostatic hyperplasia (BPH) - focus on the UK. BJU Int. 2015 Apr;115(4):508-19.

29 Coyne KS, Sexton CC, Thompson CL, Milsom I, Irwin D, Kopp ZS, et al. The prevalence of lower urinary tract symptoms (LUTS) in the USA, the UK and Sweden: results from the Epidemiology of LUTS (EpiLUTS) study. BJU Int. 2009 Aug;104(3):352-60.

30 Weibl P, Klatte T, Laurinc P, Tomaškin R, Shariat SF, Helbich M, et al. Patient's behavior and attitudes toward the management of benign prostatic hyperplasia among patients with the risk of disease progression: prospective study by "Prostate and Expectations of Treatment Epidemiology Research (PETER) study group." Wien Klin Wochenschr. 2015 May; 127(9-10):363-8.

31 van Leeuwen JH, Castro R, Busse M, Bemelmans BL. The placebo effect in the pharmacologic treatment of patients with lower urinary tract symptoms. Eur Urol. 2006 Sep;50(3): 440-52; discussion 453.

32 Eredics K, Madersbacher S, Schauer I. A Relevant Midterm (12 Months) Placebo Effect on Lower Urinary Tract Symptoms and Maximum Flow Rate in Male Lower Urinary Tract Symptom and Benign Prostatic Hyperplasia - A Meta-Analysis. Urology. 2017 Aug; 106:160-6.

33 Barry MJ, Williford WO, Chang Y, Machi M, Jones KM, Walker-Corkery E, et al. Benign prostatic hyperplasia specific health status measures in clinical research: how much change in the American Urological Association symptom index and the benign prostatic hyperplasia impact index is perceptible to patients? J Urol. 1995 Nov;154(5):1770-4.

34 Alcaraz A, Carballido-Rodríguez J, UndaUrzaiz M, Medina-López R, Ruiz-Cerdá JL, Rodríguez-Rubio F, et al. Quality of life in patients with lower urinary tract symptoms associated with BPH: change over time in reallife practice according to treatment - the QUALIPROST study. Int Urol Nephrol. 2016 May;48(5):645-56.

35 Madersbacher S, Marszalek M, Lackner J, Berger P, Schatzl G. The long-term outcome of medical therapy for BPH. Eur Urol. 2007 Jun;51(6):1522-33.

36 Jones PJ, MacDougall DE, Ntanios F, Vanstone CA. Dietary phytosterols as cholesterollowering agents in humans. Can J Physiol Pharmacol. 1997 Mar;75(3):217-27.
37 Müller C, Bracher F. Determination by GCIT/MS of phytosterols in herbal medicinal products for the treatment of lower urinary tract symptoms and food products marketed in Europe. Planta Med. 2015 May;81(7):61320.

38 Damiano R, Cai T, Fornara P, Franzese CA, Leonardi R, Mirone V. The role of Cucurbita pepo in the management of patients affected by lower urinary tract symptoms due to benign prostatic hyperplasia: a narrative review. Arch Ital Urol Androl. 2016 Jul;88(2):136-43.

39 Schilcher H, Dunzendorfer U, Ascali F. Delta 7-Sterole, das prostatotrope Wirkprinzip in Kürbissamen? Urologe B. 1987;27:316-9.

40 Schilcher H, Schneider HJ. Beurteilung von Kürbissamen in fixer Kombination mit weiteren pflanzlichen Wirkstoffen zur Behandlung des Symptomenkomplexes bei BPH. Urologe B. 1990;30:62-6.

41 Bach D. Placebokontrollierte Langzeittherapiestudie mit Kürbissamenextrakt bei $\mathrm{BPH}$ bedingten Miktionsbeschwerden. Urologe B. 2000;40(5):437-43

42 Vahlensieck W, Theurer C, Pfitzer E, Patz B, Banik N, Engelmann U. Effects of pumpkin seed in men with lower urinary tract symptoms due to benign prostatic hyperplasia in the one-year, randomized, placebo-controlled GRANU study. Urol Int. 2015;94(3): 286-95.

43 European Medicines Agency (EMA)/Committee on Herbal Medicinal Products (HMPC). Assessment report on Cucurbita pepo L., semen. EMA/HMPC/136022/2010, 20 November 2012. Available from: https:// www.ema.europa.eu/en/documents/herbalreport/final-assessment-report-cucurbitapepo-l-semen_en.pdf.

44 Ito Y, Kojma N, Suzuki A, Kurokawa M, Yamada S. Effects of SPE-Contained Fatty Acids on Bladder Muscarinic Receptors and Voiding Function in Rats. International Continence Society Meeting (ICS), Beijing, China October 15-19, 2012 [accessed 2019 May 10]. Available from: https://www.ics.org/Abstracts/Publish/134/000140.pdf.

45 Trevisan G, Rossato MF, Walker CI, Klafke JZ, Rosa F, Oliveira SM, et al. Identification of the plant steroid $\alpha$-spinasterol as a novel transient receptor potential vanilloid 1 antagonist with antinociceptive properties. J Pharmacol Exp Ther. 2012 Nov;343(2):258-69.

46 Schneider T, Rübben $\mathrm{H}$. Stinging nettle root extract (Bazoton-uno) in long term treatment of benign prostatic syndrome (BPS). Results of a randomized, double-blind, placebo controlled multicenter study after 12 months [in German]. Urologe A. 2004 Mar;43(3):302-6.

47 Bent S, Kane C, Shinohara K, Neuhaus J, Hudes ES, Goldberg H, et al. Saw palmetto for benign prostatic hyperplasia. N Engl J Med. 2006 Feb;354(6):557-66. 
48 Barry MJ, Meleth S, Lee JY, Kreder KJ, Avins AL, Nickel JC, et al.; Complementary and Alternative Medicine for Urological Symptoms (CAMUS) Study Group. Effect of increasing doses of saw palmetto extract on lower urinary tract symptoms: a randomized trial. JAMA. 2011 Sep;306(12):1344-51.

49 Chapple C, Abrams P, editors. Male Lower Urinary Tract Symptoms (LUTS). An International Consultation on Male LUTS. ICUID, International Consultation on Urological Diseases/SIU, Societé international d'Urologie, Fukuoka, Japan, September 30-October 4, 2012. Montreal, QC: Societé international d'Urologie; 2013.

50 Descazeaud A, Barry Delongchamps N, Cornu JN, Azzouzi AR, Buchon D, Benchikh A, et al. Guide dedicated to general practitioner for the management of lower urinary tract symptoms related to benign prostatic hyperplasia [in French]. Prog Urol. 2015 Jun;25(7):404-12.
51 Brenes Bermúdez FJ, Brotons Muntó F, Castiñeiras Fernández J, Cozar Olmo JM, Fernández-Pro Ledesma A, Martín Jiménez JA, et al. Documento de consenso sobre pautas de actuación y seguimiento del varón con síntomas del tracto urinario inferior secundarios a hiperplasia prostática benigna. Med General Familia. 2016;5(3):97-106.

52 Nederlandse Vereniging voor Urologie. Richtlijn: Diagnostiek en behandeling van LUTS/ BPH. Alphen aan den Rijn: Nederlandse Vereniging voor Urologie; 2017.

53 McVary KT, Roehrborn CG, Avins AL, Barry MJ, Bruskewitz RC, Donnell RF, et al. Management of Benign Prostatic Hyperplasia. Published online 2010, reviewed and validity confirmed 2014 [accessed 2017 Sep 22]. Available from: https://www.auanet.org/ guidelines/benign-prostatic-hyperplasia-(2010-reviewed-and-validity-confirmed-2014)
54 Nickel JC, Méndez-Probst CE, Whelan TF, Paterson RF, Razvi H. 2010 Update: guidelines for the management of benign prostatic hyperplasia. Can Urol Assoc J. 2010 Oct;4(5): 310-6.

55 Takeda M, Rahman MA, Salam MA, et al UAA Consensus on the management of BPH/ male LUTS (1st edition) [accessed 2017 Oct 2]. 2012. Available at: https://uaanet.org/images/BPH\%20guidelines.pdf.

56 Homma Y, Gotoh M, Yokoyama O, Masumori N, Kawauchi A, Yamanishi T, et al. JUA clinical guidelines for benign prostatic hyperplasia. Int J Urol. 2011 Nov;18(11):e1-e33.

57 Australia and New Zealand Urological Nurses Society Guideline Working Party. Management of Male Lower Urinary Tract Symptoms (LUTS) Clinical Practice Guideline. Victoria: ANZUNS; 2010. 